\title{
TWO STATES ANALYSIS FOR GRANULAR MATERIAL IN INFINITE HIGH TUBES
}

\author{
M. GÖTTLICHER \\ University of Applied Sciences Erfurt \\ Altonaer Str. 25, 99094 Erfurt, Gemany \\ m.goettlicher@t-online.de, www.fh-erfurt.de
}

Key Words: Functional, Granular Materials, FEM, Contact Problems, Infinite High Tube.

\begin{abstract}
A displacement field a pressure field and a velocity field describe the behavior of hybrid materials that is not covered by a single solid or liquid state approach. A primary analysis that is represented by a functional and its associated principle is based on a two states analysis consisting of a solid part and a pressure part. The pressure part is related to a velocity field in a secondary analysis. With respect to granulates the interaction at the walls is directed towards the avoidance of tension. Equilibrium is achieved separately for area and boundary. The distribution of the specific weight on solid and liquid parts depends on the first stress invariants.
\end{abstract}

\section{INTRODUCTION}

A static solid and a steadily flowing liquid are postulated at the same time in the same place. Internal forces interact between both components. Solutions are presented for loads and boundary conditions that oppose mere solid or mere liquid behavior.

Preferred application is an infinite high tube [4]. The static solid state requires constant vertical strain with respect to continuity. Coulomb friction represents the interaction with the walls. The steady liquid state requires constant velocities and pressures in the vertical direction. The interaction with the walls aims towards avoidance of cavitation. Unique solutions are presented for distribution of partial specific weight according to the relation of the first stress invariants and nonlinear distribution of boundary load over the cross section. Permitted solutions must avoid tension and negative partial specific weight (bracing).

The involved attributes are displacements, velocities, pressures, and partial specific weights. Displacements, pressures, and partial specific weights result from the primary analysis. Velocities result from the secondary analysis that also redefines the displacements. Load and pressure are coupled on one side, displacements, velocities, and partial specific weights are coupled on the other side.

Every physical process is time dependent. If the modifications by time are very small, a time independent approach is appropriate. Evolving avalanches and landslides, overloaded foundations and plastic steel hinges belong to the prospected applications of the solid liquid two states analysis. The related processes are in the range between time independent static analysis and time dependent liquid analysis which in the limit approaches steady state behavior. Loads and boundary conditions determine the specific weight distribution in the area, and the interacting forces between solid and liquid components in the area and at the boundaries. 


\section{GENERAL SPECIFICATIONS}

The area and boundary loads $\mathbf{p}$ and $\mathbf{b}$ consist of a solid and a liquid part.
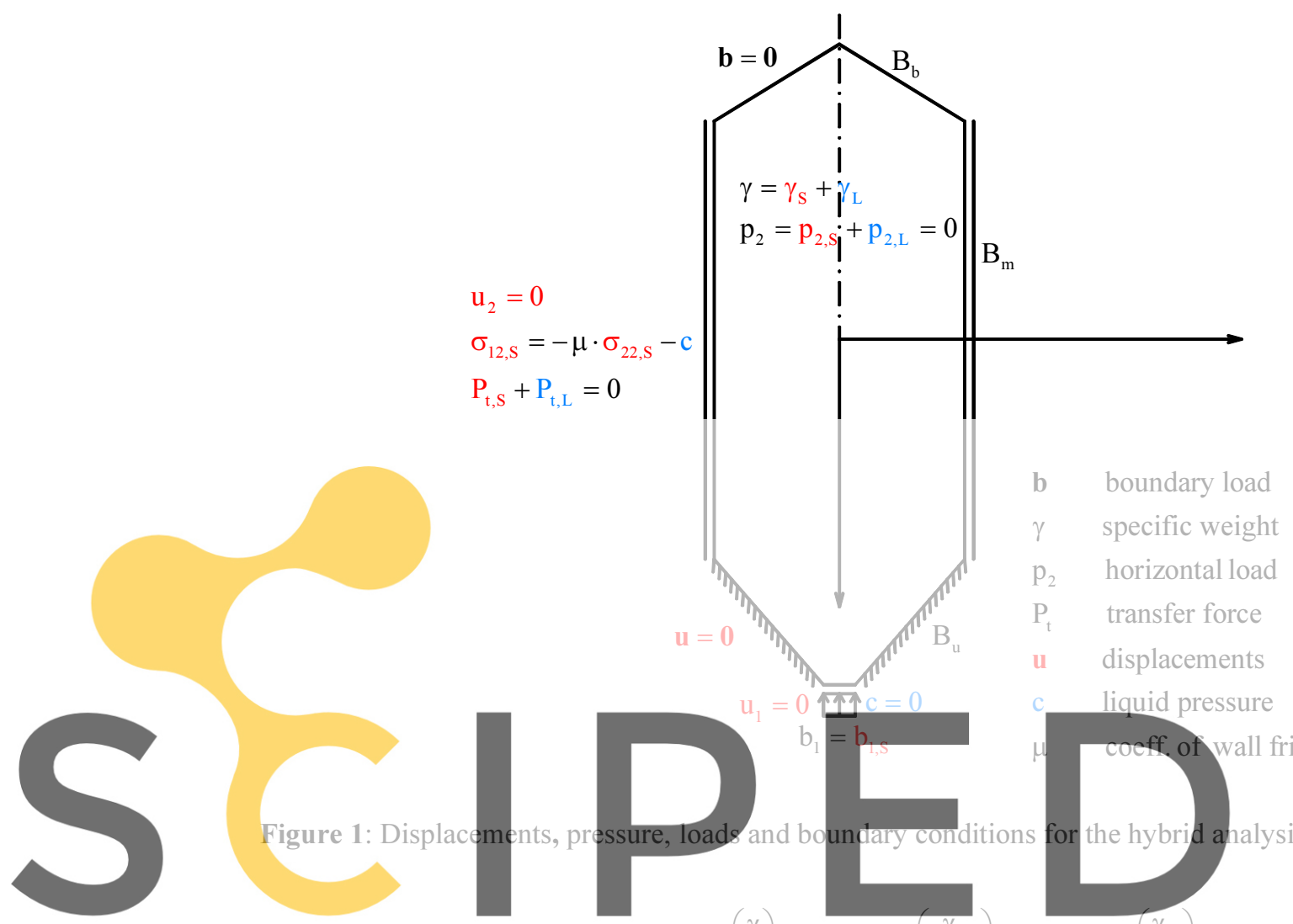

$\mathrm{p}=\mathbf{p}_{\mathrm{S}}+\mathbf{p}_{\mathrm{L}}$
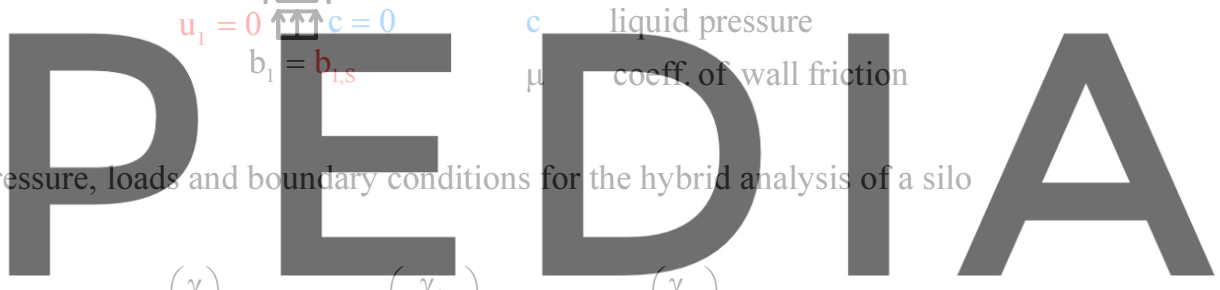

$\mathrm{p}_{\mathrm{L}}=\left(\begin{array}{l}\mathrm{L} \\ \mathrm{p}_{2}\end{array}\right)$

(1)

Register for free at https//www.scipedia.com to download the version without the watermark

$$
\mathrm{b}=\mathrm{b}_{\mathrm{S}}+\mathrm{b}_{\mathrm{L}}
$$

Solid and liquid parts are in equilibrium separately. The derivations of the solid stresses are in equilibrium with the solid area load ps. The derivations of the liquid stresses are in equilibrium with the liquid area load $\mathbf{p}_{\mathrm{L}}$.

Equilibrium equations [1][6]:

$$
\begin{aligned}
\mathbf{D}^{\mathrm{T}} \boldsymbol{\sigma}_{\mathrm{S}}=-\mathbf{p}_{\mathrm{S}} \quad \mathbf{D}^{\mathrm{T}} & =\left(\begin{array}{ccc}
\frac{\partial}{\partial \mathrm{x}_{1}} & 0 & \frac{\partial}{\partial \mathrm{x}_{2}} \\
0 & \frac{\partial}{\partial \mathbf{x}_{2}} & \frac{\partial}{\partial \mathrm{x}_{1}}
\end{array}\right) \\
\mathbf{D}^{\mathrm{T}} \boldsymbol{\sigma}_{\mathrm{L}} & =-\mathbf{p}_{\mathrm{L}}
\end{aligned}
$$

Linear elastic stress strain relations are applied to the solid part. Stress velocity relations for incompressible, slowly moving, viscous liquids without inertia and without convection are applied to the liquid part. The liquid pressure $\mathrm{c}$ appears as an additional unknown.

Solid stresses: 


$$
\boldsymbol{\sigma}_{\mathrm{S}}=\mathbf{E} \boldsymbol{\varepsilon}=\mathbf{E}(\mathbf{D u}) \quad \mathbf{E}=\frac{\mathrm{E}}{(1+v)(1-2 v)} \cdot\left(\begin{array}{ccc}
1-v & v & 0 \\
v & 1-v & 0 \\
0 & 0 & \frac{1-2 v}{2}
\end{array}\right)
$$

Liquid stresses:

$$
\boldsymbol{\sigma}_{\mathrm{L}}=\left(\begin{array}{l}
\sigma_{11, \mathrm{~L}} \\
\sigma_{22, \mathrm{~L}} \\
\sigma_{12, \mathrm{~L}}
\end{array}\right)
$$

Incompressibility:

$$
\sigma_{11, \mathrm{~L}}=\sigma_{22, \mathrm{~L}}=\mathrm{c}
$$

Viscosity:

$$
\sigma_{12, L}=\eta \cdot\left(\frac{\partial v_{1}}{\partial x_{2}}+\frac{\partial v_{2}}{\partial x_{1}}\right)
$$

Natural boundary conditions:

At the loaded boundary $\mathrm{B}_{\mathrm{b}}$ the stresses of the single parts are in equilibrium with the loads

$\mathbf{b}_{\mathrm{S}}$ and $\mathbf{b}_{\mathrm{L}}$ of the sing
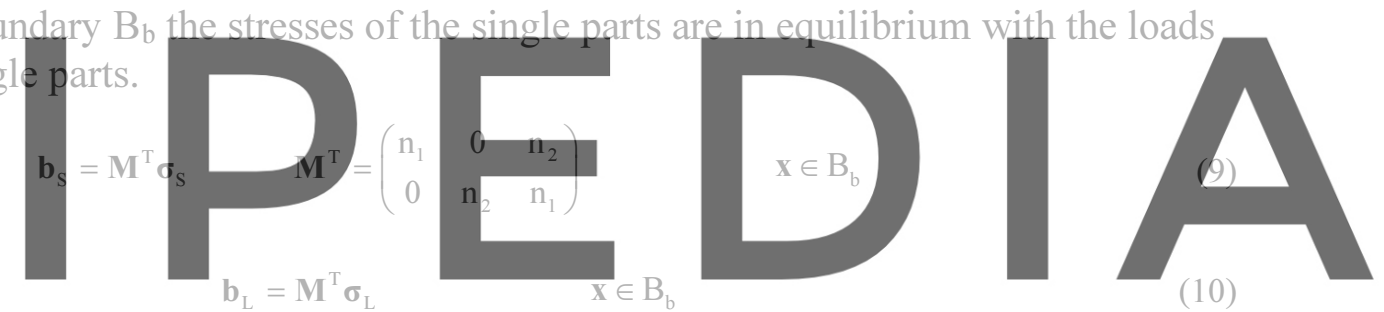

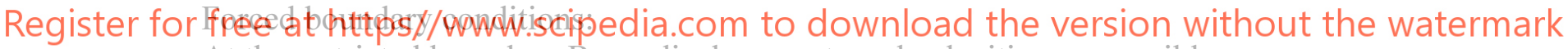
At the restricted boundary $\mathrm{B}_{\mathrm{u}}$ no displacements and velocities are possible.

$$
\begin{array}{ll}
\mathbf{u}=\mathbf{0} & \mathbf{x} \in \mathrm{B}_{\mathrm{u}} \\
\mathbf{v}=\mathbf{0} & \mathbf{x} \in \mathrm{B}_{\mathrm{u}}
\end{array}
$$

Mixed boundary conditions:

At the part $\mathrm{B}_{\mathrm{m}}$ of the boundary the tangential load is related to the normal stress according to Coulomb friction for the solid part. Tangential load and normal stress are set equal for the liquid part with respect to the avoidance of tension. No movement is possible normally to the boundary. The matrix $\mathbf{Q}$ represents the influence of the direction of the boundary. The transfer load $\mathbf{b}_{\mathrm{T}}$ rules the distribution of the boundary load on solid and liquid parts.

$$
\begin{aligned}
&\left.\begin{array}{l}
\mathbf{b}_{\mathrm{S}}=\mu \mathbf{Q}^{\mathrm{T}} \boldsymbol{\sigma}_{\mathrm{S}}-\mathbf{b}_{\mathrm{T}} \\
\mathrm{u}_{\mathrm{n}}=0
\end{array}\right\} \quad \begin{aligned}
\mathbf{x} \in \mathrm{B}_{\mathrm{m}} & \operatorname{sign}\left(\mathrm{u}_{\mathrm{t}}\right)
\end{aligned} \mathbf{Q}^{\mathrm{T}}=\left(\begin{array}{ccc}
-\mathrm{n}_{1}^{2} \mathrm{n}_{2} & \mathrm{n}_{2}^{3} & 0 \\
\mathrm{n}_{1}^{3} & -\mathrm{n}_{1} \mathrm{n}_{2}^{2} & 0
\end{array}\right) \\
& \mathbf{b}_{\mathrm{L}}=\mathbf{Q}^{\mathrm{T}} \boldsymbol{\sigma}_{\mathrm{L}}+\mathbf{b}_{\mathrm{T}} \\
& \mathrm{v}_{\mathrm{n}}=0
\end{aligned} \quad \begin{aligned}
\mathbf{x} \in \mathrm{B}_{\mathrm{m}} & \operatorname{sign}\left(\mathrm{v}_{\mathrm{t}}\right)
\end{aligned}
$$




\section{FUNCTIONALS AND PRINCIPLES}

Primary analysis:

The primary analysis includes displacements and pressure fields. Based on the constitutive equations a functional is postulated for plane continua $[5,6]$ :

$$
\Pi=\frac{1}{2} \int_{\mathrm{A}} \boldsymbol{\varepsilon}^{\mathrm{T}} \mathbf{E} \boldsymbol{\varepsilon} \mathrm{dA}+\frac{1}{2} \mu \int_{\mathrm{B}_{\mathrm{m}}} \mathbf{u}^{\mathrm{T}} \mathbf{Q}^{\mathrm{T}} \mathbf{E} \boldsymbol{\varepsilon} \mathrm{dB}+\int_{\mathrm{B}_{\mathrm{m}}} \mathbf{u}^{\mathrm{T}} \mathbf{Q}^{\mathrm{T}} \mathbf{c} \mathrm{dB}-\int_{\mathrm{A}} \mathbf{u}^{\mathrm{T}} \mathbf{p} \mathrm{d} \mathrm{A}-\int_{\mathrm{B}_{\mathrm{b}}} \mathbf{u}^{\mathrm{T}} \mathbf{b} \mathrm{dB}
$$

An elastic solid interacts with an incompressible liquid which is represented by a pressure field. Associated principle:

$$
\int_{\mathrm{A}} \delta \boldsymbol{\varepsilon}^{\mathrm{T}} \mathbf{E} \boldsymbol{\varepsilon} \mathrm{d} \mathrm{A}+\int_{\mathrm{B}_{\mathrm{m}}} \delta \mathbf{u}^{\mathrm{T}} \mathbf{Q}^{\mathrm{T}}[\mu \mathbf{E} \boldsymbol{\varepsilon}+\mathbf{c}] \mathrm{dB}-\int_{\mathrm{A}} \delta \mathbf{u}^{\mathrm{T}} \mathbf{p} \mathrm{d} \mathrm{A}-\int_{\mathrm{B}_{\mathrm{b}}} \delta \mathbf{u}^{\mathrm{T}} \mathbf{b} \mathrm{dB}=0
$$

Secondary analysis:

The vertical area load (specific weight) is distributed according to the relation of the first stress invariants to solid and liquid. The principle for the resulting secondary analysis includes an additional velocity field:

$$
\Pi=\frac{1}{2} \int_{\mathrm{A}} \varepsilon^{\mathrm{T}} \mathbf{E} \varepsilon \mathrm{d} \mathrm{A}+\frac{1}{2} \int_{\mathrm{A}} \dot{\varepsilon}_{12} \eta \dot{\varepsilon}_{12} \mathrm{~d} \mathrm{~A}+\frac{1}{2} \mu \int_{\mathrm{B}_{\mathrm{m}}} \mathbf{u}^{\mathrm{T}} \mathbf{Q}^{\mathrm{T}} \mathbf{E} \varepsilon \mathrm{dB}+\int_{\mathrm{B}_{\mathrm{m}}} \mathbf{v}^{\mathrm{T}} \mathbf{Q}^{\mathrm{T}} \mathbf{c} \mathrm{dB}-\ldots
$$
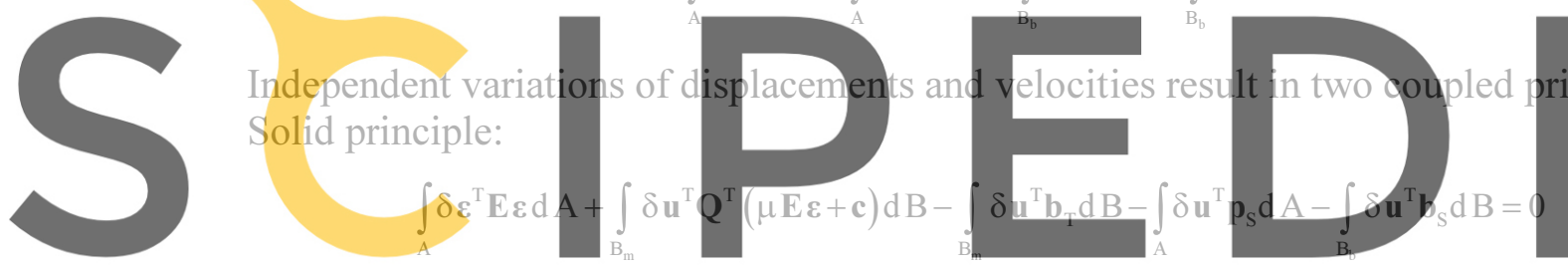

\subsection{Infinite high tube}

Functionals and principles are restricted to the special case of an infinite high tube.

Primary analysis:

Functional:

$$
\Pi=\frac{1}{2} \int_{A}(\mathbf{D u})^{\mathrm{T}} \mathbf{E}(\mathbf{D u}) \mathrm{d} A+\frac{1}{2} \int_{\mathrm{B}_{\mathrm{m}}} \mathrm{u}_{1} \mu \sigma_{22, S} \mathrm{~dB}+\int_{\mathrm{B}_{\mathrm{m}}} \mathrm{u}_{1} \mathrm{cdB}-\int_{\mathrm{A}} \mathrm{u}_{1} \gamma \mathrm{d} \mathrm{A}-\int_{\mathrm{A}} \mathrm{u}_{2} \frac{\partial \mathrm{c}}{\partial \mathrm{x}_{2}} \mathrm{~d} \mathrm{~A}-\int_{\mathrm{B}_{\mathrm{b}}} \mathrm{u}_{1}\left(\mathrm{~b}_{1}-\mathrm{c}\right) \mathrm{dB}
$$

Principle:

$$
\int_{A} \delta(\mathbf{D u})^{\mathrm{T}} \mathbf{E}(\mathbf{D u}) \mathrm{d} A+\int_{\mathrm{B}_{\mathrm{m}}} \delta \mathrm{u}_{1}\left(\mu \sigma_{22, \mathrm{~S}}+\mathrm{c}\right) \mathrm{d} \mathrm{B}-\int_{\mathrm{A}} \delta \mathrm{u}_{1} \gamma \mathrm{dA}-\int_{\mathrm{A}} \delta \mathrm{u}_{2} \frac{\partial \mathbf{c}}{\partial \mathbf{x}_{2}} \mathrm{~d} \mathrm{~A}-\int_{\mathrm{B}_{\mathrm{b}}} \delta \mathrm{u}_{1}\left(\mathrm{~b}_{1}-\mathrm{c}\right) \mathrm{dB}=0
$$

Secondary analysis:

Functional: 


$$
\begin{gathered}
\Pi=\frac{1}{2} \int_{\mathrm{A}}(\mathbf{D u})^{\mathrm{T}} \mathbf{E}(\mathbf{D} \mathbf{u}) \mathrm{d} \mathrm{A}+\frac{1}{2} \int_{\mathrm{A}} \frac{\partial \mathrm{v}_{1}}{\partial \mathrm{x}_{2}} \eta \frac{\partial \mathrm{v}_{1}}{\partial \mathrm{x}_{2}} \mathrm{~d} \mathrm{~A}+\frac{1}{2} \int_{\mathrm{B}_{\mathrm{m}}} \mathrm{u}_{1} \mu \sigma_{22, \mathrm{~S}} \mathrm{~d} \mathrm{~B}+\int_{\mathrm{B}_{\mathrm{m}}} \mathrm{u}_{1} \mathrm{cdB}-\ldots \\
\ldots-\int_{\mathrm{A}} \mathrm{u}_{1} \gamma_{\mathrm{S}} \mathrm{d} \mathrm{A}-\int_{\mathrm{A}} \mathrm{v}_{1}\left(\gamma-\gamma_{\mathrm{S}}\right) \mathrm{d} \mathrm{A}-\int_{\mathrm{A}} \mathrm{u}_{2} \frac{\partial \mathrm{c}}{\partial \mathrm{x}_{2}} \mathrm{~d} \mathrm{~A}-\int_{\mathrm{B}_{\mathrm{b}}} \mathrm{u}_{1}\left(\mathrm{~b}_{1}-\mathrm{c}\right) \mathrm{dB}
\end{gathered}
$$

Coupled Principles:

$$
\begin{gathered}
\int_{\mathrm{A}} \delta(\mathbf{D u})^{\mathrm{T}} \mathbf{E}(\mathbf{D u}) \mathrm{d} A+\int_{\mathrm{B}_{\mathrm{m}}} \delta \mathrm{u}_{1}\left(\mu \sigma_{22, \mathrm{~S}}+\mathrm{c}\right) \mathrm{dB}-\mathrm{P}_{\mathrm{b}}-\int_{\mathrm{A}} \delta \mathrm{u}_{1} \gamma_{\mathrm{S}} \mathrm{d} \mathrm{A}-\int_{\mathrm{A}} \delta \mathrm{u}_{2} \frac{\partial \mathrm{c}}{\partial \mathrm{x}_{2}} \mathrm{dA}-\int_{\mathrm{B}_{\mathrm{b}}} \delta \mathrm{u}_{1}\left(\mathrm{~b}_{1}-\mathrm{c}\right) \mathrm{dB}= \\
\int_{\mathrm{A}} \delta \frac{\partial \mathrm{v}_{1}}{\partial \mathrm{x}_{2}} \eta \frac{\partial \mathrm{v}_{1}}{\partial \mathrm{x}_{2}} \mathrm{dA}+\int_{\mathrm{B}_{\mathrm{m}}} \delta \mathrm{v}_{1} \mathrm{~dB}+\mathrm{P}_{\mathrm{b}}-\int_{\mathrm{A}} \delta \mathrm{v}_{1}\left(\gamma-\gamma_{\mathrm{S}}\right) \mathrm{d} \mathrm{A}=0
\end{gathered}
$$

\section{APPROXIMATION}

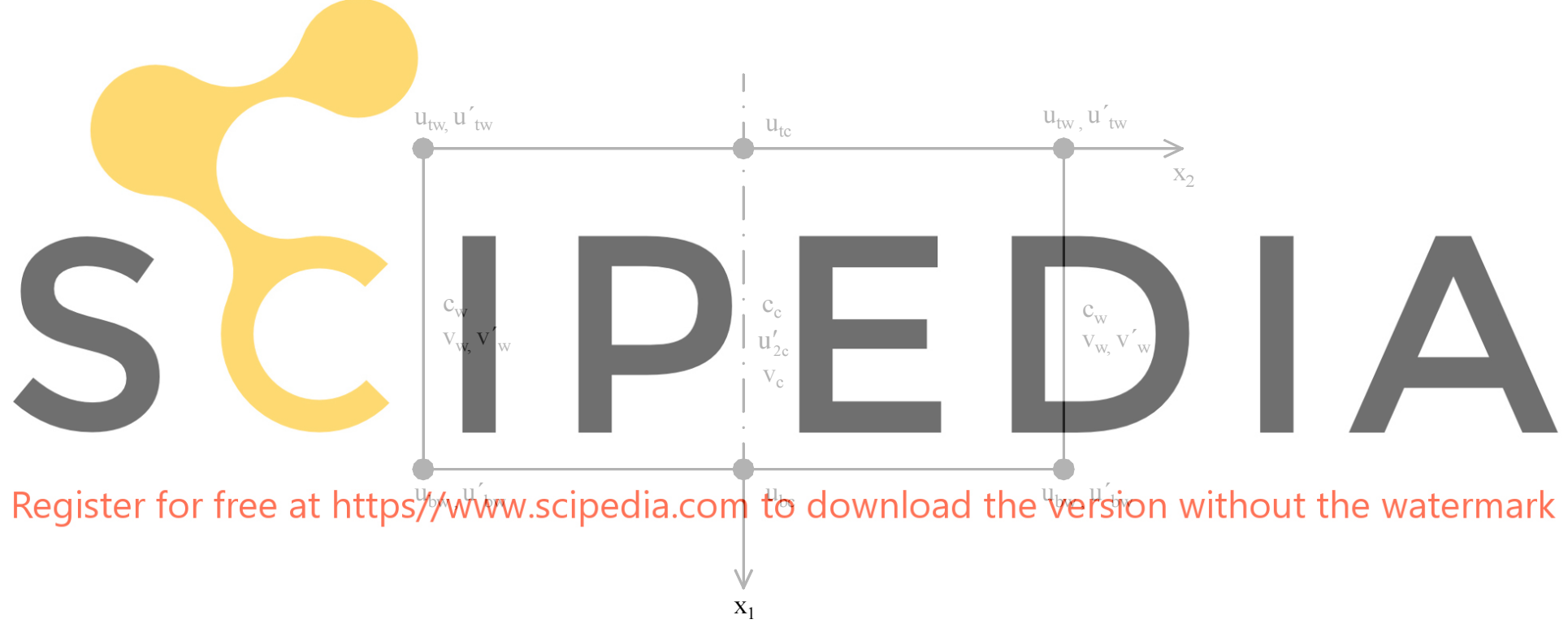

Figure 2: Nodal values for the interpolation functions

A fourth order approximation of the vertical displacement $u_{1}$ in the horizontal direction and a linear approximation in the vertical direction require six degrees of freedom with respect to the symmetry of the tube. A single degree of freedom is required for a cubic approximation of the horizontal displacement $\mathrm{u}_{2}$ since it is assumed to be constant in the vertical direction and to be zero in the center and at the walls of the tube. This degree of freedom is the horizontal strain $\overline{\mathrm{u}}_{2}$ in the center which is the first derivation of the horizontal displacement $u_{2 c}^{\prime}$. The digits $t$ and $b$ of the nodal values refer to the top face and the bottom face. The digits $\mathrm{c}$ and $\mathrm{w}$ refer to the center and the walls (Figure 2).

$$
\begin{aligned}
& \mathbf{u}=\mathbf{F}^{\mathrm{T}} \overline{\mathbf{u}}=\left(\begin{array}{cc}
\mathbf{f}^{\mathrm{T}} & 0 \\
\mathbf{0}^{\mathrm{T}} & \mathrm{f}
\end{array}\right) \cdot\left(\begin{array}{l}
\overline{\mathbf{u}}_{1} \\
\overline{\mathbf{u}}_{2}
\end{array}\right) \\
& \overline{\mathbf{u}}_{1}^{\mathrm{T}}=\left(\begin{array}{llllll}
\mathrm{u}_{\mathrm{tc}} & \mathrm{u}_{\mathrm{tw}} & \mathrm{u}_{\mathrm{tw}}^{\prime} & \mathrm{u}_{\mathrm{bc}} & \mathrm{u}_{\mathrm{bw}} & \mathrm{u}_{\mathrm{bw}}^{\prime}
\end{array}\right)
\end{aligned}
$$


Displacement at the walls:

$$
\mathrm{u}_{\mathrm{w}}=\mathbf{h}^{\mathrm{T}} \overline{\mathbf{u}}_{\mathrm{w}}=\frac{\mathrm{H}-\mathrm{x}_{1}}{\mathrm{H}} \mathrm{u}_{\mathrm{tw}}+\frac{\mathrm{x}_{1}}{\mathrm{H}} \mathrm{u}_{\mathrm{bw}}
$$

Restriction of the vertical tube:

$$
\begin{gathered}
\mathrm{u}_{\mathrm{bw}}=0 \\
\mathrm{u}_{\mathrm{tc}}=\mathrm{u}_{\mathrm{bc}}+\mathrm{u}_{\mathrm{tw}} \\
\mathrm{u}_{\mathrm{tw}}^{\prime}=\mathrm{u}_{\mathrm{bw}}^{\prime}
\end{gathered}
$$

Strain interpolation matrix:

$$
\mathbf{B}=\mathbf{D} \mathbf{F}^{\mathrm{T}}
$$

The liquid pressure $\mathrm{c}$ is assumed to be constant in the vertical direction and quadratic in the horizontal direction. Due to symmetry two degrees of freedom are required. These degrees of freedom are the liquid pressure $\mathrm{c}_{\mathrm{c}}$ in the center and $\mathrm{c}_{\mathrm{w}}$ at the walls (Figure 4).

$$
\mathrm{c}=\mathrm{g}^{\mathrm{T}} \overline{\mathrm{c}}
$$

The boundary load $\mathbf{b}$ acts at the top face and the bottom face of the slice. The quadratic distribution of the vertical component $b_{1}$ depends on values $b_{c}$ at the center and $b_{w}$ at the walls. The linear distribution walls. It is zero in the center. Integration of area load:
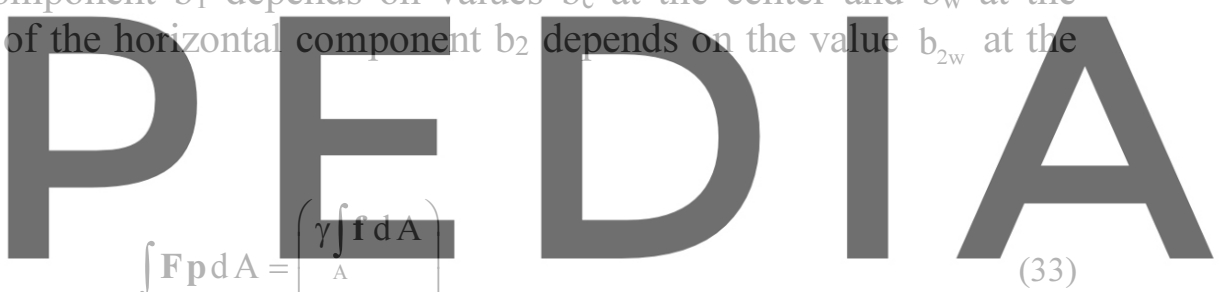

Register for free at https//www.scipedia.com to download the version without the watermark

The horizontal area load is an interaction between solid and liquid parts:

$$
\mathrm{p}_{2, \mathrm{~L}}=-\mathrm{p}_{2, \mathrm{~S}}
$$

Integration of partial area load:

$$
\int_{A} \mathbf{F} \mathbf{p}_{S} \mathrm{dA}=\left(\begin{array}{c}
\gamma_{\mathrm{S}} \int_{\mathrm{A}} \mathbf{f d A} \\
-\mathrm{p}_{2 \mathrm{w}, \mathrm{S}} \int_{\mathrm{A}} \mathrm{fgdA}
\end{array}\right)
$$

$\mathrm{p}_{2 \mathrm{w}, \mathrm{S}} \quad$ Solid part (S) of the horizontal force $\mathrm{p}_{2}$ at the walls (w)

A fourth order approximation of the vertical velocity requires three degrees of freedom with respect to symmetry. For absent convection, the horizontal velocity is zero.

$$
\begin{aligned}
& \mathrm{v}_{1}=\mathbf{f}_{\mathrm{v}}^{\mathrm{T}} \overline{\mathbf{v}}_{1} \\
& \overline{\mathbf{v}}_{1}=\left(\begin{array}{c}
\mathrm{v}_{\mathrm{a}} \\
\mathrm{v}_{\mathrm{b}} \\
\mathrm{v}_{\mathrm{b}}^{\prime}
\end{array}\right)
\end{aligned}
$$




$$
\frac{\partial \mathbf{v}_{1}}{\partial \mathbf{x}_{2}}=\frac{\partial \mathbf{f}_{\mathrm{v}}}{\partial \mathrm{x}_{2}} \overline{\mathbf{v}}_{1}=\mathbf{b}_{\mathrm{v}}^{\mathrm{T}} \overline{\mathbf{v}}_{1}
$$

It follows for the principles (23 and 24):

$$
\begin{gathered}
\delta \overline{\mathbf{u}}^{\mathrm{T}} \int_{\mathrm{A}} \mathbf{B} \mathbf{E} \mathbf{B}^{\mathrm{T}} \mathrm{d} \mathrm{A} \overline{\mathbf{u}}+\delta \overline{\mathbf{u}}_{\mathrm{w}}^{\mathrm{T}} \mu \int_{\mathrm{B}_{\mathrm{m}}} \mathbf{h} \frac{\partial \mathrm{f}}{\partial \mathrm{x}_{2}} \mathbf{e}_{2}^{\mathrm{T}} \mathbf{B}^{\mathrm{T}} \mathrm{dB} \overline{\mathbf{u}}+\delta \overline{\mathbf{u}}_{\mathrm{w}}^{\mathrm{T}} \int_{\mathrm{B}_{\mathrm{m}}} \mathbf{h} \mathbf{g}^{\mathrm{T}} \mathrm{dB} \overline{\mathbf{c}}-\delta \overline{\mathbf{u}}_{\mathrm{w}}^{\mathrm{T}} \mathrm{P}_{\mathrm{b}}-\ldots \\
\ldots-\delta \overline{\mathbf{u}}_{1}^{\mathrm{T}} \gamma_{\mathrm{S}} \int_{\mathrm{A}} \mathbf{f} \mathrm{dA}-\delta \overline{\mathbf{u}}_{2} \int_{\mathrm{A}} \mathrm{f} \frac{\partial \mathbf{g}^{\mathrm{T}}}{\partial \mathbf{x}_{2}} \mathrm{dA} \overline{\mathbf{c}}-\delta \overline{\mathbf{u}}_{1}^{\mathrm{T}} \int_{\mathrm{B}_{\mathrm{b}}} \mathbf{f} \mathbf{g}^{\mathrm{T}} \mathrm{dB}\left(\overline{\mathbf{b}}_{1}-\overline{\mathbf{c}}\right)+=\mathbf{0} \\
\delta \overline{\mathbf{v}}_{1}^{\mathrm{T}} \int_{\mathrm{A}} \mathbf{b}_{\mathrm{v}} \eta \mathbf{b}_{\mathrm{v}}^{\mathrm{T}} \mathrm{d} \mathrm{A} \overline{\mathbf{v}}_{1}+\delta \mathrm{v}_{\mathrm{b}} \mathrm{P}_{\mathrm{b}}-\delta \overline{\mathbf{v}}_{1}^{\mathrm{T}}\left(\gamma-\gamma_{\mathrm{S}}\right) \int_{\mathrm{A}} \mathbf{f}_{\mathrm{v}} \mathrm{dA}=\mathbf{0}
\end{gathered}
$$

The two principles are appropriate to determine displacements and velocities. The additional two liquid pressures result from the two displacement restrictions (zero at the bottom of the wall and constant vertical strain). The additional constant partial specific $\gamma_{S}$ weight results from the velocity restriction (zero at the bottom of the wall).

\section{APPLICATION}

Specific weight, Poisson's ratio, and coefficient of wall friction in the applications represent grain [2]. The modulus of elasticity is chosen according to [3] (e.g. peat).
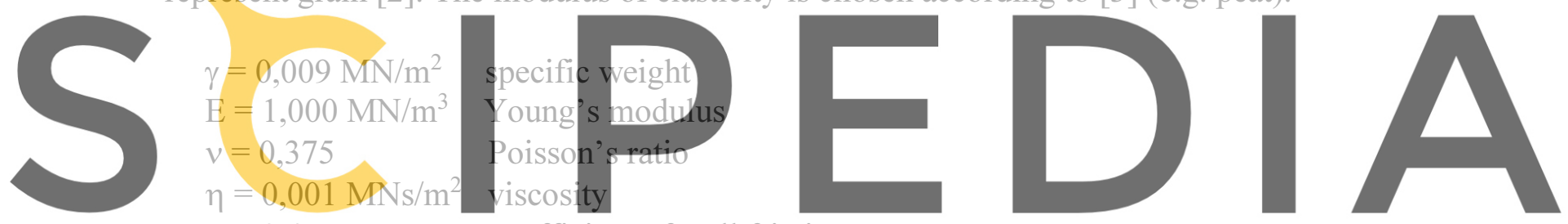

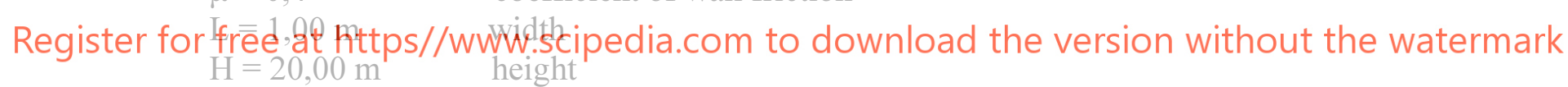

\subsection{Constant distribution over the cross section}

Mere solid solution (Fig. 3a):

$$
\sigma_{11}=0,01875 \mathrm{MN} / \mathrm{m}^{2}
$$

Mere liquid solution (Fig. 3d):

$$
\sigma_{11}=0,0045 \mathrm{MN} / \mathrm{m}^{2} \quad \mathrm{c}=0,0045 \mathrm{MN} / \mathrm{m}^{2}
$$

In the center of a very high tube constant distribution of loads and stresses is likely. For linear increasement of the boundary load from the mere liquid state to the mere solid state, the liquid pressure declines linear and the horizontal stress increases linear. However, the relation of the first stress invariants, that characterizes the contribution of solid and liquid parts, is highly nonlinear (Table 1). Solid stresses, displacements, velocities, and partial specific weights follow the nonlinear relation of the first stress invariants (Table 2). 


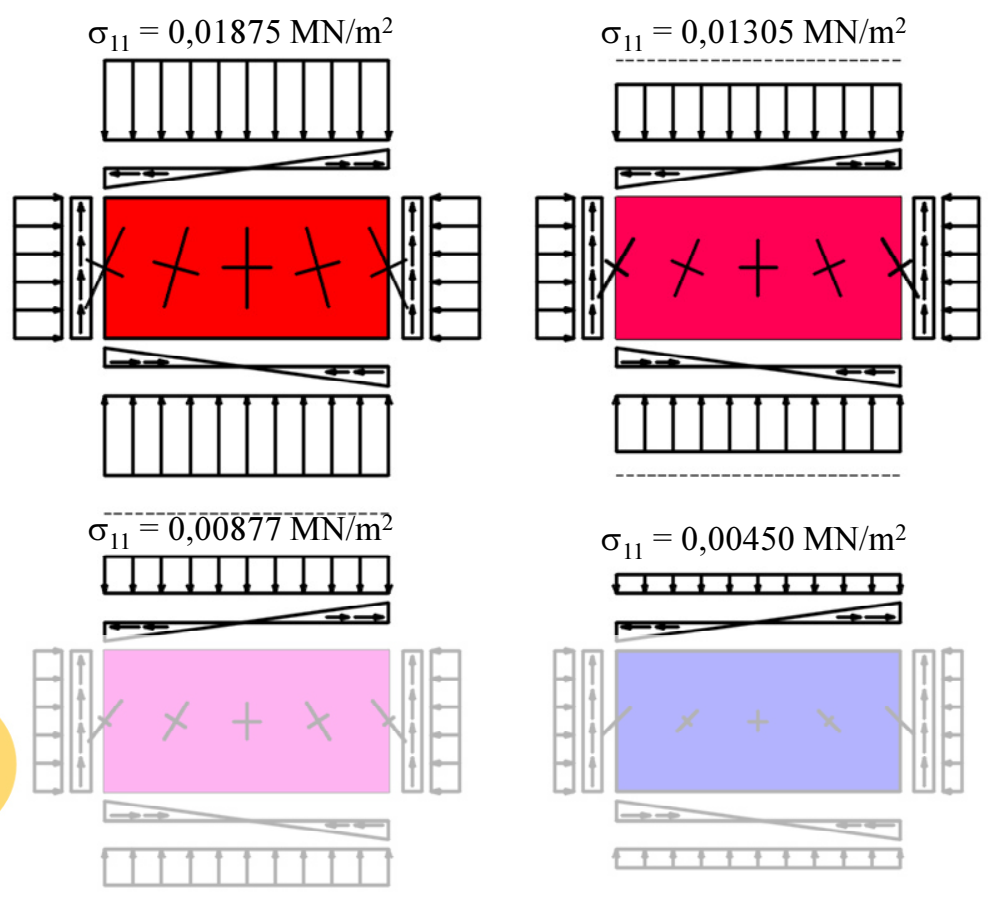

Figure 3: Transformation from the solid state (a, red) by the hybrid states (b, dark red and $\mathbf{c}$, violet) to the liquid

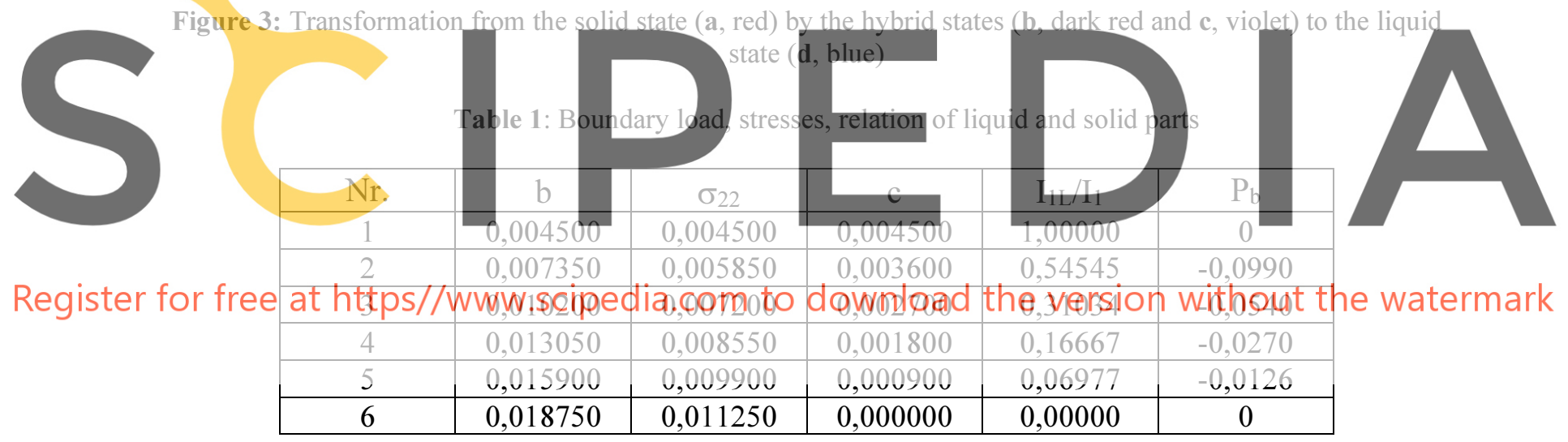

Table 2: Partial specific weight, displacements, and velocities

\begin{tabular}{|c|c|c|c|c|c|c|}
\hline Nr. & $\sigma_{11, \mathrm{~S}}$ & $\sigma_{22, \mathrm{~S}}$ & $\gamma_{\mathrm{S}}$ & $\gamma_{\mathrm{L}}$ & $\mathrm{u}_{\mathrm{bc}}$ & $\mathrm{v}_{\mathrm{c}}$ \\
\hline 1 & 0,00000 & 0,00000 & 0 & 0,0090 & 0 & 1,125 \\
\hline 2 & 0,00375 & 0,00225 & 0,0041 & 0,0049 & 0,001392 & 0,61875 \\
\hline 3 & 0,00750 & 0,00450 & 0,0072 & 0,0028 & 0.002166 & 0,33750 \\
\hline 4 & 0,01125 & 0,00675 & 0,0085 & 0,0015 & 0.002623 & 0,16875 \\
\hline 5 & 0,01500 & 0,00900 & 0,0094 & 0,0006 & 0,002877 & 0,07875 \\
\hline 6 & 0,01875 & 0,01125 & 0,0090 & 0,0000 & 0,003094 & 0 \\
\hline
\end{tabular}

\subsection{Nonlinear distribution over the cross section:}

For prescribed nonlinear boundary load, and for prescribed partial specific weight distribution according to the primary analysis, the resulting stresses, deformations, and velocities are unique (Table 3 ).

Lower pressure in the centre: 
Starting from the mere solid case only a decline of the vertical stresses in the center is possible to avoid tension. For lower vertical stresses in the center (Figure $4 \mathrm{~b}$ ) the partial solid stresses dominate in the center (red color). At the walls, the liquid stresses finally exceed the solid stresses (violet color) If the vertical stresses in the center continue to decrease the solid stresses at the walls enter the not permitted tension range.
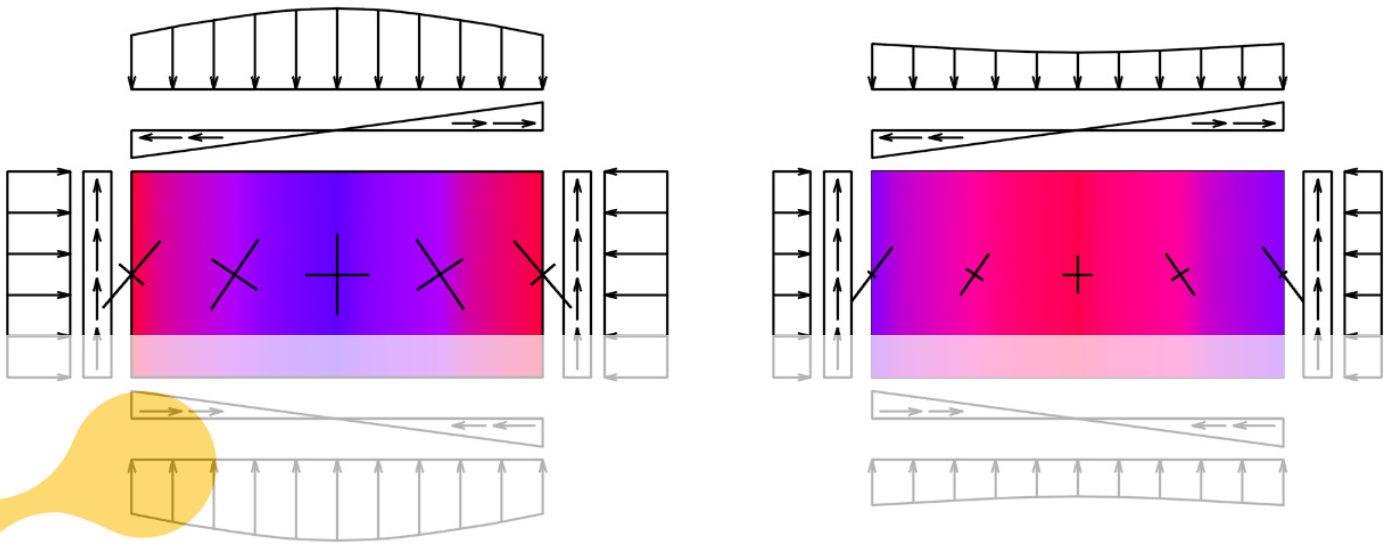

Figure 4: Primary solid behavior at the walls and nearly liquid behavior in the center (a, left). Primary liquid behavior at the walls and nearly solid behavior in the center (b, right).
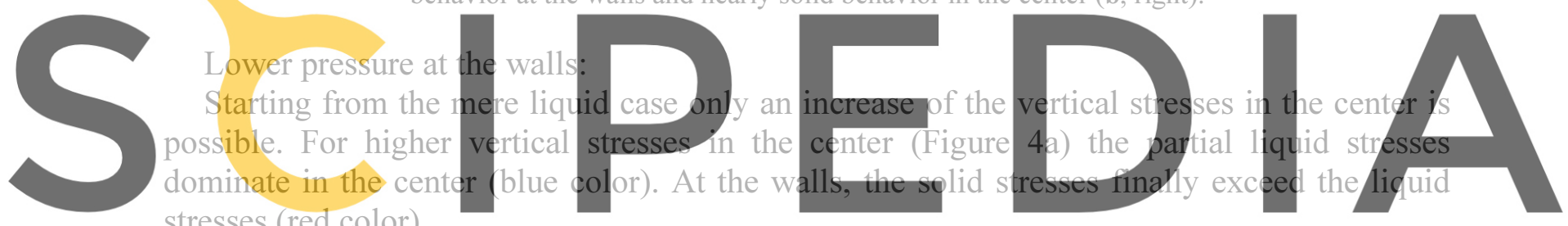

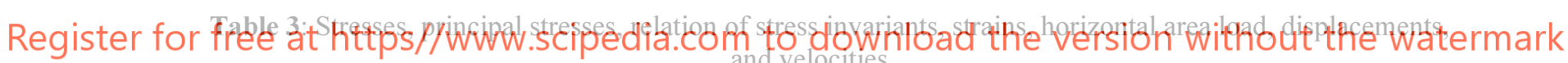

\begin{tabular}{|c|c|c|c|c|c|c|}
\hline Figure: & \multicolumn{3}{|c|}{$4 \mathrm{a}$} & \multicolumn{3}{c|}{$4 \mathrm{~b}$} \\
\hline $\mathrm{x}_{2}$ & 0,5 & 0,25 & 0,0 & 0,5 & 0,25 & 0,0 \\
\hline$\sigma_{11}$ & 0,008775 & 0,001198 & 0,013050 & 0,007350 & 0,006994 & 0,005925 \\
\hline$\sigma_{22}$ & 0,010125 & 0,010125 & 0,010125 & 0,006375 & 0,006375 & 0,006375 \\
\hline $\mathrm{c}$ & 0,000750 & 0,008766 & 0,011437 & 0,003250 & 0,005922 & 0,006812 \\
\hline $\mathrm{p}_{2}$ & 0,042750 & 0,021375 & 0 & $-0,014250$ & $-0,007125$ & 0 \\
\hline$\sigma_{12}$ & 0,00450 & 0,00225 & 0 & 0,00450 & 0,00225 & 0 \\
\hline $\mathrm{I}_{1, \mathrm{~L}} / \mathrm{I}_{1}$ & 0,793 & 0,079 & 0,987 & 0,733 & 0,316 & 0,158 \\
\hline $\mathrm{u}_{\mathrm{b}}$ & 0 & 0,000116 & 0,000464 & 0 & 0,000774 & 0,003094 \\
\hline $\mathrm{v}$ & 0 & 0,23906 & 0,95625 & 0 & 0,25781 & 1,03125 \\
\hline
\end{tabular}

Transformation:

The mere solid solution (Figure 3a) turns to the hybrid solution (Figure $4 \mathrm{~b}$ ) if the constant stress function turns to a concave stress function. While the stress level decreases it approaches the mere liquid solution (Figure 3d). While the constant stress function turns into a convex stress function (which is barely possible) it turns to the hybrid solution (Figure 4a). 
While the stress level increases it finally approaches the mere solid solution again (Figure $3 \mathrm{~d}$ ).

Table 4: Transformation from the solid state (Fig. 3a) by the hybrid state (Fig. 4b) to the liquid state (Fig. 3d) and back to the solid state by the hybrid state (Fig. $4 a),\left(x_{2}=0,5\right)$

\begin{tabular}{|c|c|c|c|c|c|}
\hline Fig.: & $3 \mathrm{a}$ & $4 \mathrm{a}$ & $3 \mathrm{~d}$ & $4 \mathrm{~b}$ & $3 \mathrm{a}$ \\
\hline$\sigma_{11, \mathrm{c}}$ & 0,01875 & 0,013050 & 0,004500 & 0,005925 & 0,01875 \\
\hline $\mathrm{u}_{\mathrm{bc}}$ & 0,003094 & 0,000464 & 0 & 0,003094 & 0,003094 \\
\hline $\mathrm{v}_{\mathrm{c}}$ & 0 & 0,95625 & 1,12500 & 1,03125 & 0 \\
\hline$\sigma_{11, \mathrm{w}}$ & 0,01875 & 0,008775 & 0,004500 & 0,007350 & 0,01875 \\
\hline$\sigma_{22}$ & 0,01125 & 0,010125 & 0,004500 & 0,004650 & 0,01125 \\
\hline $\mathrm{c}$ & 0 & 0,000750 & 0,004500 & 0,004400 & 0 \\
\hline $\mathrm{p}_{2}$ & 0 & 0,042750 & 0 & $-0,014250$ & 0 \\
\hline$\sigma_{12}$ & 0,00450 & 0,00450 & 0,00450 & 0,00450 & 0,00450 \\
\hline $\mathrm{I}_{1, \mathrm{~L}} / \mathrm{I}_{1}$ & 0 & 0,793 & 1,00 & 0,733 & 0 \\
\hline $\mathrm{P}_{\mathrm{b}}$ & 0 & $-0,126$ & 0 & $-0,150$ & 0 \\
\hline
\end{tabular}

Table 4 shows the development at the walls $\left(\mathrm{x}_{2}=0,50 \mathrm{~m}\right)$ during this process. (The related

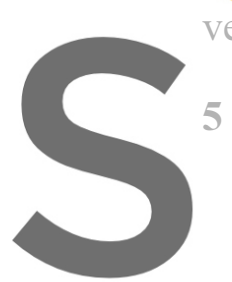
vertical stress in the $c$

\section{CONCLUSIONS \\ applications. It}

The computational method presented

place at the same time. The linearity of
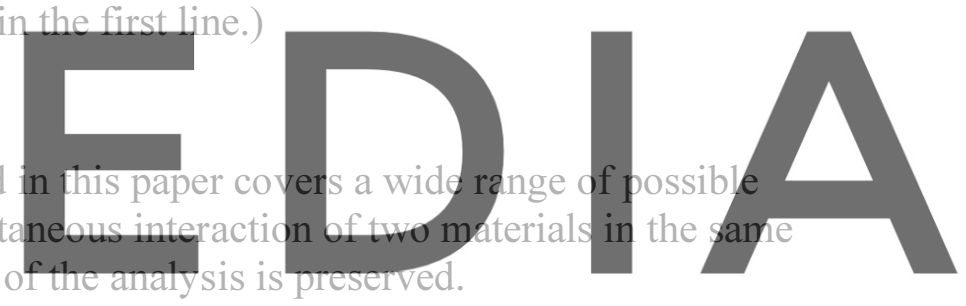

The unavoidable nonlinear effects are covered by obvious a priori considerations as

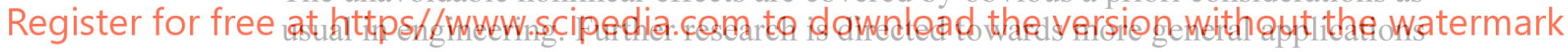

and the investigation of the usefulness of the numerical analysis that has been

developed for an infinite high tube.

\section{REFERENCES}

[1] KJ. Bathe, Finite-Elemente-Methoden, Springer-Verlag, 2012.

[2] S. Ehmann, K. Morgen, C. Ruckenbrod, Silos. Beton-Kalender, Band 2, Ernst \& Sohn, 2016.

[3] J. Engel, Geotechnik, Bautabellen für Ingenieure. Bundesanzeiger Verlag, 2016.

[4] M. Göttlicher, Hybrid Analysis for Continua with Solid and Liquid Properties in Infinite High Tubes. VIII International Conference on Computational Methods for Coupled Problems in Science and Engineering, Barcelona, 2019.

[5] K.A. Reckling, and P. Gummert, Mechanik, Springer-Verlag, 2014

[6] O.C. Zienkiewicz and R.C. Taylor, The finite element method, $6^{\text {th }}$ Edition, Elsevier, 2005. 